\title{
Tight junction disruption by cadmium in an in vitro human airway tissue model
}

\author{
Xuefei Cao ${ }^{1}$, Haixia Lin ${ }^{1}$, Levan Muskhelishvili², John Latendresse ${ }^{2}$, Patricia Richter ${ }^{3}$ and Robert H Heflich ${ }^{4 *}$
}

\begin{abstract}
Background: The cadmium (Cd) present in air pollutants and cigarette smoke has the potential of causing multiple adverse health outcomes involving damage to pulmonary and cardiovascular tissue. Injury to pulmonary epithelium may include alterations in tight junction (TJ) integrity, resulting in impaired epithelial barrier function and enhanced penetration of chemicals and biomolecules. Herein, we investigated mechanisms involved in the disruption of TJ integrity by $\mathrm{Cd}$ exposure using an in vitro human air-liquid-interface (ALI) airway tissue model derived from normal primary human bronchial epithelial cells.
\end{abstract}

Methods: ALI cultures were exposed to noncytotoxic doses of $\mathrm{CdCl}_{2}$ basolaterally and TJ integrity was measured by Trans-Epithelial Electrical Resistance (TEER) and immunofluorescence staining with TJ markers. PCR array analysis was used to identify genes involved with TJ collapse. To explore the involvement of kinase signaling pathways, cultures were treated with $\mathrm{CdCl}_{2}$ in the presence of kinase inhibitors specific for cellular Src or Protein Kinase C (PKC).

Results: Noncytotoxic doses of $\mathrm{CdCl}_{2}$ resulted in the collapse of barrier function, as demonstrated by TEER measurements and Zonula occludens-1 (ZO-1) and occludin staining. $\mathrm{CdCl}_{2}$ exposure altered the expression of several groups of genes encoding proteins involved in TJ homeostasis. In particular, down-regulation of select junction-interacting proteins suggested that a possible mechanism for $\mathrm{Cd}$ toxicity involves disruption of the peripheral junctional complexes implicated in connecting membrane-bound TJ components to the actin cytoskeleton. Inhibition of kinase signaling using inhibitors specific for cellular Src or PKC preserved the integrity of TJs, possibly by preventing occludin tyrosine hyperphosphorylation, rather than reversing the down-regulation of the junctioninteracting proteins.

Conclusions: Our findings indicate that acute doses of Cd likely disrupt TJ integrity in human ALI airway cultures both through occludin hyperphosphorylation via kinase activation and by direct disruption of the junction-interacting complex.

Keywords: Cadmium, Airway air-liquid-interface (ALI) culture, Tight junction, Occludin phosphorylation, Intracellular junctional interacting proteins

\section{Introduction}

Cadmium $(\mathrm{Cd})$ is a highly toxic heavy metal present in environmental pollution and tobacco smoke [1]. For the general population, cigarette smoke is a major source of Cd exposure, with approximately $10-20 \%$ of the $\mathrm{Cd}$ in mainstream smoke inhaled and $50 \%$ of the inhaled dose absorbed via the respiratory system. Thus, smokers usually have significantly higher urine and blood Cd levels than nonsmokers [2,3]. Repeated low doses of Cd, such

\footnotetext{
* Correspondence: robert.heflich@fda.hhs.gov

${ }^{4}$ Division of Genetic and Molecular Toxicology, 3900 NCTR Rd, Jefferson, AR 72079, USA

Full list of author information is available at the end of the article
}

as those from daily cigarette smoking, accumulate in various organs, leading to pulmonary, cardiovascular, and renal toxicity [4-6].

It is postulated that $\mathrm{Cd}$ disturbs tissue homeostasis via multiple mechanisms, including inducing apoptosis and oxidative stress, inhibiting DNA repair, promoting DNA demethylation, interfering with essential metals, and disrupting E-cadherin-mediated cell adhesion [6]. Recent studies conducted in renal tubule epithelial cells, rat seminiferous epithelial cells, and human lung epithelial cells revealed that exposure to $\mathrm{Cd}$ also can disrupt intercellular tight junctions (TJs) and that the modes of action for the 
resulting toxicity likely are tissue-specific [7-10]. Given that pulmonary disease is a common outcome of $\mathrm{Cd}$ related exposures and that the human airway is exposed to $\mathrm{Cd}$ through, e.g., cigarette smoke, airway epithelium could be a major target for Cd-mediated TJ disruption. Whether or not such toxicity occurs and the underlying mechanism for this toxicity, therefore, warrants further investigation.

The TJ is a highly dynamic molecular structure involved in maintaining and regulating tissue permeability and polarity [11]. The basic structure of TJs comprises a network of transmembrane proteins and cytoplasmic plaques connected by adaptor proteins [12]. Dysregulation of TJ permeability has been implicated in a variety of pathological conditions in pulmonary tissues, including asthma and lung cancer [13]. Possible molecular targets leading to TJ disruption have been studied extensively. In addition to the well-understood membrane components that are mainly involved in mediating intercellular adhesion, the cytoplasmic fractions of the TJs increasingly have been recognized for their essential roles in regulating $\mathrm{TJ}$ biogenesis and transmitting cellular signals between different components of the TJ plaques [12]. It is believed that the expression of $\mathrm{TJ}$-associated proteins as well as their subcellular localization and phosphorylation status are essential in maintaining the barrier function of TJs in response to various stimuli, such as oxidative stress, inflammation, and cytokines $[14,15]$. The function of phosphorylation modification may involve both modulating interactions between $\mathrm{TJ}$-associated molecules and signal transduction upon internal and external stimulation $[16,17]$. Several protein kinases and phosphatases have been identified that are directly involved in occludin phosphorylation on multiple residues [18].

Well-differentiated human airway air-liquid-interface (ALI) tissue cultures derived from normal primary human bronchial epithelial (NHBE) cells develop mature TJs and retain all major cell types found in human airway epithelium. Thus, they have emerged as an advanced in vitro tissue model that closely recapitulates in vivo airway epithelial tissue architecture and function. In this study, we explored molecular events underlying Cd-mediated $\mathrm{TJ}$ disruption in human airway ALI tissue models.

\section{Methods}

Reagents

$\mathrm{CdCl}_{2}$ was purchased from MP Biomedicals (CAS No. 10108-64-2; purity > 99.0\%; Santa Ana, CA). Mouse and rabbit anti-occludin antibodies and rabbit anti-ZO-1 antibody were purchased from Invitrogen (Grand Island, NY). Mouse anti-VAP-33 antibody was obtained from BD Biosciences (San Jose, CA). Rabbit anti-TJAP1 antibody was obtained from Abcam (Cambridge, MA). Mouse
anti-GAPDH and rabbit anti-cingulin antibodies were purchased from Sigma-Aldrich (St. Louis, MO). Mouse anti-p-Tyr antibody PY99, c-Src kinase inhibitor I, and pan Protein Kinase C (PKC) inhibitor (GF 109203X) were purchased from Santa Cruz Biotechnology (Dallas, TX). Mouse anti-p63 and rabbit anti-Ki-67 antibodies were obtained from Thermo Scientific (Pittsburgh, PA) and Lab Vision Corporation (Fremont, CA), respectively. Horseradish peroxidase-conjugated goat anti-mouse and goat anti-rabbit antibodies were purchased from Vector Laboratories (Burlingame, CA). Alexa Fluor 488 goat antimouse IgG and Alexa Fluor ${ }^{\circ} 594$ goat anti-rabbit IgG were obtained from Invitrogen. IRDye 680RD goat anti-mouse IgG, IRDye 680RD goat anti-rabbit IgG, and IRDye $800 \mathrm{CW}$ goat anti-mouse IgG secondary antibodies were purchased from LI-COR (Lincoln, NE).

\section{Airway epithelial ALI culture}

NHBE cells cryopreserved at Passage 1 were purchased from Lonza (Walkersville, MD). Cells were quickly thawed at $37^{\circ} \mathrm{C}$ upon receipt and expanded on collagen-coated P100 tissue culture dishes in bronchial epithelium growth medium (BEGM, Lonza). ALI cultures were established using a PneumaCult ALI medium kit and by following the manufacturer's instructions (STEMCELL Technologies, Vancouver, Canada). Briefly, after the cells reached approximately $70 \%$ confluency in the P100 tissue culture dishes, they were induced by incubation for $24 \mathrm{~h}$ in Induction Medium provided by the ALI medium kit. The induced cells were collected with $0.025 \%$ Trypsin-EDTA, resuspended in Expansion Medium provided by the medium kit, and seeded onto 24-well collagen-coated PET cell culture inserts (BD Biosciences, San Jose, CA). The cells were incubated in Expansion Medium added to both the apical and basolateral chambers of the culture inserts until they reached $100 \%$ confluency. The apical medium then was removed and the cells were fed basolaterally only with kit-supplied serum- and bovine pituitary extract-free Maintenance Medium. The basolateral medium was replaced every 2 or 3 days for approximately 4 weeks until the cultures became fully differentiated.

\section{Histology}

ALI cultures were washed briefly with phosphate-buffered saline (PBS, pH 7.4) and fixed in 10\% neutral buffered formalin for $48 \mathrm{~h}$. The membranes were excised from the culture inserts with a surgical blade and embedded in paraffin. Five- $\mu \mathrm{m}$-thick tissue sections were cut, mounted on slides, and deparaffinized by processing through a series of xylene and ethanol solutions. Hematoxylin and eosin (H\&E) staining was conducted using a Leica Autostainer. Deparaffinized tissue sections also were stained for p63, Ki-67, and mucus-producing goblet cells. For p63 and Ki-67 staining, antigens were retrieved by boiling the 
tissue sections in $0.01 \mathrm{M}$ citrate buffer, $\mathrm{pH}$ 6.0, for $15 \mathrm{~min}(3 \times 5 \mathrm{~min} / \mathrm{run})$ using a microwave oven. After the slides were cooled to room temperature, they were washed in $\mathrm{dH}_{2} \mathrm{O}$ for $5 \mathrm{~min}$. The slides then were treated with $3 \%$ hydrogen peroxide containing $1 \%$ sodium azide for $10 \mathrm{~min}$ to quench endogenous peroxidases. Following blocking the nonspecific binding in $0.5 \%$ casein for $20 \mathrm{~min}$, the slides were incubated for $1 \mathrm{~h}$ at room temperature with antibodies for p63 or Ki-67 diluted 1:100 and 1:200, respectively, in PBS containing $1 \%$ bovine serum albumin (BSA, Sigma-Aldrich). After the conclusion of the primary antibody incubation, the slides were incubated with the respective horseradish peroxidase-conjugated secondary antibodies for $30 \mathrm{~min}$ at room temperature. Staining was developed with diaminobenzidine (DAB, Sigma-Aldrich) substrate for $5 \mathrm{~min}$ at room temperature. Sections then were counter-stained with hematoxylin and mounted with Permount mounting medium (Thermo Scientific). Mouse IgG, rabbit IgG, or PBS was added in the place of primary antibodies to serve as the negative staining controls.

Mucus-producing goblet cells were identified by periodic acid Schiff's (PAS) staining. Slides with deparaffinized tissue sections were incubated in periodic acid solution for $5 \mathrm{~min}$ at room temperature. The slides then were washed with $\mathrm{H}_{2} \mathrm{O}$ and incubated in Schiff's reagent for $30 \mathrm{~min}$ at room temperature. The slides were washed again in running tap water and counter-stained with hematoxylin.

\section{Cd exposure conditions}

Treatment medium containing various concentrations of $\mathrm{CdCl}_{2}$ was prepared by diluting a stock solution in Maintenance Medium. Exposure to $\mathrm{CdCl}_{2}$ was carried out from the basolateral side of the ALI cultures to mimic the systemic (blood) exposure of airway epithelium to $\mathrm{Cd}$. Four hundred $\mu \mathrm{L}$ treatment medium were added to the basolateral compartments for 24,48 , or $72 \mathrm{~h}$. After the treatment, the basolateral medium was removed and both the apical and basolateral surfaces of the cultures were washed with PBS once before proceeding to the following analyses.

\section{Trans-epithelial electrical resistance (TEER)}

TEER measurements were made using an Endohm- 6 tissue resistance chamber and an epithelial volt-ohmmeter (EVOM2, World Precision Instruments, Sarasota, FL). The EVOM2 was calibrated using a test electrode prior to the measurement. The culture insert was positioned in the center of the Endohm- 6 chamber containing $1 \mathrm{~mL}$ of the electrolyte solution $\left(0.9 \% \mathrm{NaCl}, 1.25 \mathrm{mM} \mathrm{CaCl}_{2}\right.$, $10 \mathrm{mM}$ HEPES); and $300 \mu \mathrm{L}$ of the electrolyte solution were added to the apical chamber of the culture insert. TEER values were taken 3 times per data point and an average was calculated. An empty culture insert was used to correct for the background resistance. Three cultures were used for each treatment concentration and time point.

\section{Cell viability}

Cell viability was measured using the CellTiter $96^{\circ}$ Aqueous Non-radioactive Cell Proliferation MTS Assay (Promega, Madison, WI). The MTS assay is based on the bio-reduction of a tetrazolium compound (MTS) to a soluble formazan product by metabolically active cells. The amount of formazan product formed is directly proportional to the number of live cells, thus providing a quantitative measure of cell viability. After TEER measurement, $200 \mu \mathrm{L}$ fresh Maintenance Medium containing the MTS/PMS reagent were added to the apical compartment of the culture inserts and incubated for $1 \mathrm{~h}$ at $37^{\circ} \mathrm{C}$ to allow the metabolic conversion of tetrazolium to formazan. One hundred and twenty $\mu \mathrm{L}$ of the apical medium then were transferred to a clear 96-well plate. The optical density of the apical medium was measured at $490 \mathrm{~nm}$ using a Synergy H4 plate reader (BioTek, Winooski, VT). Triplicate cultures were used for each treatment concentration and time point.

\section{Immunofluorescence}

Double immunofluorescence labeling with Zonula occludens-1 (ZO-1) and occludin was conducted by following the method described previously [19]. Prior to the treatment, the accumulated mucus was removed by washing the apical side of the ALI cultures thoroughly with PBS. The cultures then were treated for $24 \mathrm{~h}$ with various concentrations of $\mathrm{CdCl}_{2}$ in the presence or absence of inhibitors of c-Src or PKC. At the end of the treatment, the cultures were washed with PBS twice and permeabilized in methanol for $30 \mathrm{~min}$ at $-20^{\circ} \mathrm{C}$. After washing with PBS for $15 \mathrm{~min}(3 \times 5 \mathrm{~min} /$ wash $)$, the cultures were incubated for $1 \mathrm{~h}$ with $100 \mu \mathrm{L}$ of goat anti-rabbit ZO-1 and goat anti-mouse occludin antibodies (both diluted 1:500 in PBS containing 10\% normal goat serum), followed by washing with PBS 3 times $(5 \mathrm{~min} /$ wash) to remove the unbound antibodies. One hundred $\mu \mathrm{L}$ of Alexa Fluor 488 goat anti-mouse IgG or Alexa Fluor ${ }^{\circ} 594$ goat anti-rabbit IgG (both diluted 1:500 in PBS with 10\% normal goat serum) were added to the apical chamber and the cultures were incubated in dye-conjugated secondary antibodies for $1 \mathrm{~h}$ in the dark. The cultures were again washed 3 times with PBS (5 $\mathrm{min} /$ wash) and post-fixed with freshly prepared $4 \%$ paraformaldehyde for $30 \mathrm{~min}$ at room temperature in the dark. The membranes were excised from the plastic insert support using a surgical blade and mounted on a positively charged microscope slide with $30 \mu \mathrm{L}$ VECTASHIELD ${ }^{\circ}$ Mounting Medium containing 4,6-diamidino- 
2-phenylindole (DAPI) (Vector Laboratories). Images were captured with a Nikon fluorescence microscope equipped with appropriate filters.

\section{Human tight junction PCR array}

Total RNA was isolated using an miRNeasy Mini Kit (Qiagen, Gaithersburg, MD) by following the manufacturer's instructions. The quality of the total RNA was assessed using the Bio-Rad Experion Automated Electrophoresis System (Hercules, CA) and RNA samples with an RNA Integrity Number $\geq 9.5$ were used for cDNA synthesis. Four hundred ng of the total RNA were used to synthesize cDNAs using a Qiagen $\mathrm{RT}^{2}$ First Strand Kit.

Gene expression profiles were generated using human TJ RT ${ }^{2}$ Profiler PCR arrays (SABiosciences, Gaithersburg, MD) and a 7500 Fast Real-Time PCR System (Applied Biosystems, Carlsbad, CA). The vehicle-treated control was conducted in quadruplicate $(\mathrm{N}=4)$ and each $\mathrm{CdCl}_{2}$ treatment was performed in triplicate $(\mathrm{N}=3)$. Ct values were normalized using the house-keeping gene, Hprt1, prior to data analysis. Gene expression changes were calculated using $\mathrm{RT}^{2}$ Profiler PCR Array Data Analysis v3.5 software (available on-line at: http://www.sabiosciences.com/pcrarraydataanalysis.php). Gene expression was compared between the vehicle-treated control and the two $\mathrm{CdCl}_{2}$ treatments using the $\Delta \Delta \mathrm{Ct}$ method. Student's $t$-test conducted on quadruplicate $2^{-\Delta \Delta C t}$ values for each gene in the vehicle-treated control and on triplicate values for the $\mathrm{CdCl}_{2}$-treated groups was used to assess the significance of differences in gene expression. Genes with fold changes $\geq 1.5$ and $p$-values $\leq 0.05$ were selected as candidates that respond to $\mathrm{Cd}$ exposure.

Principal component analysis (PCA) was conducted using ArrayTrack (U.S. FDA/National Center for Toxicological Research, Jefferson, AR). Briefly, PCR array data corrected for backgrounds were imported into ArrayTrack and normalized using Total Intensity Normalization. Expression ratios (treated/control) were $\log _{2}$-transformed. The transformed data were used for PCA to evaluate the effect of $\mathrm{Cd}$ exposure. Among the nine principal components considered by the ArrayTrack software, the program selected the first, second and third components as the most informative; these accounted for 45.79, 31.70 and $10.12 \%$ of the variance in the correlation matrix, respectively.

\section{Immunoblotting}

Total cell lysates were prepared using the Pierce M-PER Mammalian Protein Extraction Reagent supplemented with $1 \times$ SIGMAFAST ${ }^{\text {tw }}$ Protease Inhibitor Cocktail. Protein concentrations were determined using the BCA protein assay. Ten $\mu \mathrm{g}$ aliquots of total protein were loaded onto a NuPage ${ }^{\odot}$ Novex $^{\oplus} 4-12 \%$ Bis-Tris gel (Invitrogen) and proteins were separated in MES running buffer at
$200 \mathrm{~V}$ for $35 \mathrm{~min}$. The separated proteins then were transferred to a nitrocellulose membrane at $30 \mathrm{~V}$ for $1 \mathrm{~h}$ and blocked with Odyssey Blocking Buffer (LI-COR) for $1 \mathrm{~h}$ at room temperature with gentle rocking. Subsequently, the membrane was incubated overnight at $4{ }^{\circ} \mathrm{C}$ with antibodies diluted in Odyssey Blocking Buffer with 0.1\% Tween-20. Proteins were visualized with IRDye-conjugated secondary antibodies and a LI-COR Odyssey CLx Imaging System.

\section{Co-immunoprecipitation}

Co-immunoprecipitation (co-IP) was conducted using the Pierce Co-IP kit according to the manufacturer's instructions. Briefly, $40 \mu \mathrm{g}$ of rabbit anti-occludin antibody were immobilized with AminoLink Plus Coupling Resin and stored at $4^{\circ} \mathrm{C}$ until the analysis. Cells were lysed in $100 \mu \mathrm{L}$ IP Lysis/Wash Buffer supplemented with $1 \times$ SIGMAFAST $T^{\mathrm{m}}$ Protease Inhibitor Cocktail. Protein concentrations were determined using the BCA protein assay and $500 \mu \mathrm{g}$ of total protein were precleared through $40 \mu \mathrm{L}$ of Control Agarose Resin to minimize nonspecific protein binding. Equal volumes of the precleared cell lysate were added to the antibody-coupled resin and incubated overnight at $4^{\circ} \mathrm{C}$ with gentle mixing. The protein complex was eluted in $35 \mu \mathrm{L}$ Elution Buffer and $20 \mu \mathrm{L}$ of the elute were analyzed for $\mathrm{p}$-Tyr by immunoblotting.

\section{Statistical analysis}

All data are presented as mathematical mean values \pm standard error of the mean. Differences between the vehicle-treated control and $\mathrm{CdCl}_{2}$-treated groups were assessed by using one-way ANOVA followed by Dunnett's test provided by the SigmaPlot version 11 statistics package. Data were tested for normality. $p$-values $\leq 0.05$ were considered statistically significant.

\section{Results}

\section{Morphological evaluation of the ALI tissue model}

The morphology of differentiated ALI cultures was evaluated by histological methods 5 weeks after the initial seeding onto the permeable membrane support. $H \& E$ staining of the paraffin-embedded tissue sections indicated that the ALI cultures were fully differentiated into a pseudostratified mucociliary epithelium, with cells resembling goblet cells interspersed among ciliated cells along the apical side of the cultures (Figure 1A). Different types of epithelial cells were further distinguished by cell-specific markers. The cuboidal-shaped basal cells were identified by staining with the progenitor cell marker, p63 (Figure 1B). Cells expressing p63 were found exclusively along the basolateral side of the ALI culture. Cells undergoing active proliferation also were located only on the basolateral side, as demonstrated by staining with the cellular proliferation marker, Ki-67 (Figure 1C). 


\section{A}

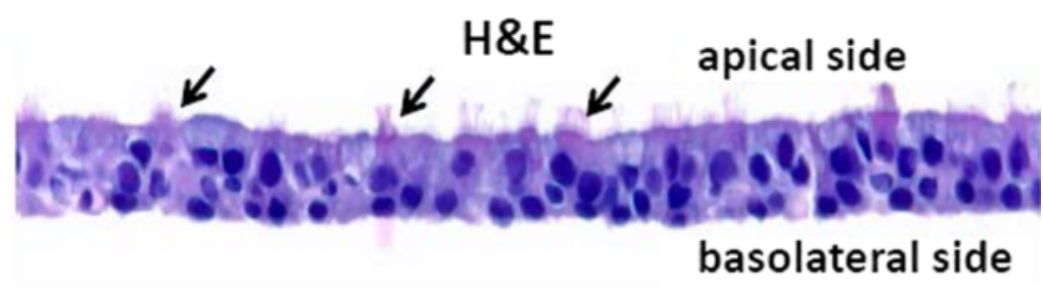

B

p63

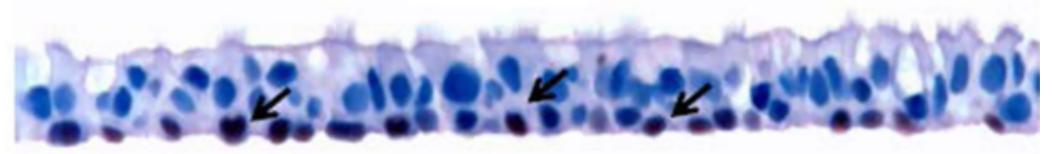

C

Ki-67

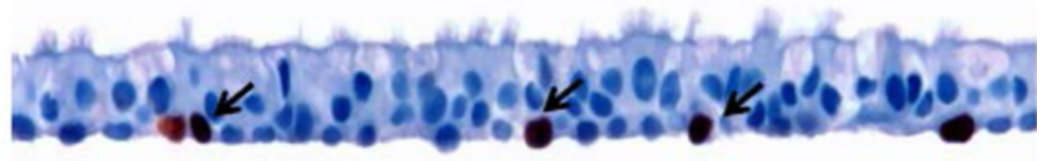

D

PAS

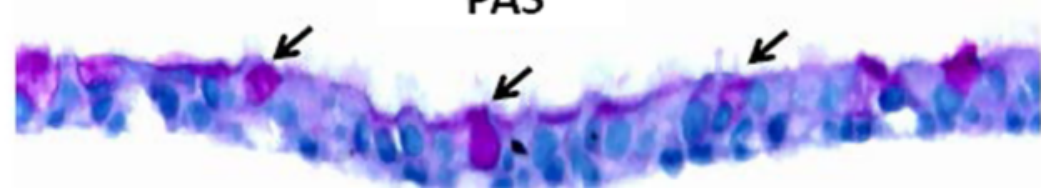

Figure 1 Morphological characterization of ALI human airway cultures. ALI cultures were fixed in 10\% formalin 5 weeks after the initial seeding onto the permeable membrane support. Tissue sections were stained with H\&E (A), p63 (B), Ki67 (C), and PAS (D). Examples of positively stained cells are indicated by arrows. The arrows in (A), (B), (C), and (D) indicate ciliated cells, basal cells, actively proliferating cells, and goblet cells, respectively.

PAS staining, which detects the glycoprotein and glycolipid components in mucin, was used to identify the mucus-secreting goblet cells (Figure 1D). Consistent with the $H \& E$ staining, PAS-positive goblet cells were distributed along the apical side of the culture. Residual secreted mucus also was detected on the apical side by PAS staining.

\section{$\mathrm{CdCl}_{2}$ reduces TEER values and induces cellular toxicity}

TEER measurements were made on $\mathrm{CdCl}_{2}$-treated ALI cultures, followed by the evaluation of cytotoxicity with the MTS assay. Cultures were treated basolaterally with various concentrations of $\mathrm{CdCl}_{2}$ for 24,48 , or $72 \mathrm{~h}$ as described in the Methods section. $\mathrm{CdCl}_{2}$ caused dose- and timedependent decreases in TEER values. Treatment with $100 \mu \mathrm{M} \mathrm{CdCl}_{2}$ produced an approximate $50 \%$ reduction in TEER following both the 24- and 48-h exposures (Figure 2A), and increasing the treatment duration to $72 \mathrm{~h}$ further decreased the TEER values close to background levels (i.e., the resistance of an empty culture insert). Treatments with 10 and $30 \mu \mathrm{M} \mathrm{CdCl}$ had only minor effects on TEER values, whereas the integrity of the cultures was completely disrupted with a dose of $300 \mu \mathrm{M} \mathrm{CdCl}$ at all sampling times.

The MTS assay revealed a trend in dose-response toxicity similar to that observed with the TEER measurements (Figure $2 \mathrm{~B}$ ). Doses up to $100 \mu \mathrm{M} \mathrm{CdCl}_{2}$ did not significantly decrease cell viability at any of the time points tested. A dose of $300 \mu \mathrm{M}$, however, completely inhibited the metabolic activities of the cultures at all sampling time points, indicating that the cultures were no longer viable. The $\mathrm{IC}_{50}$ value for $\mathrm{CdCl}_{2}$ determined by the MTS assay fell between $100 \mu \mathrm{M}$ and $300 \mu \mathrm{M}$, which was higher than that of approximately $100 \mu \mathrm{M}$ estimated by TEER measurements after the 24-h treatment. Given that the $100 \mu \mathrm{M} \mathrm{CdCl}_{2}$ was noncytotoxic and induced an approximately $50 \%$ reduction in TEER measurement, we selected concentrations of 30 , 50 , and $100 \mu \mathrm{M}$ for our subsequent mechanism studies.

\section{Acute treatment with $\mathrm{CdCl}_{2}$ disrupts $\mathrm{TJ}$ integrity}

The drop in TEER values indicated a possible disruption of $\mathrm{TJ}$ function caused by $\mathrm{CdCl}_{2}$ treatment. Thus, alterations in $\mathrm{TJ}$ integrity in response to $\mathrm{CdCl}_{2}$ exposures were further investigated using immunofluorescence staining of two TJ markers, ZO-1 and occludin. In vehicle-treated 

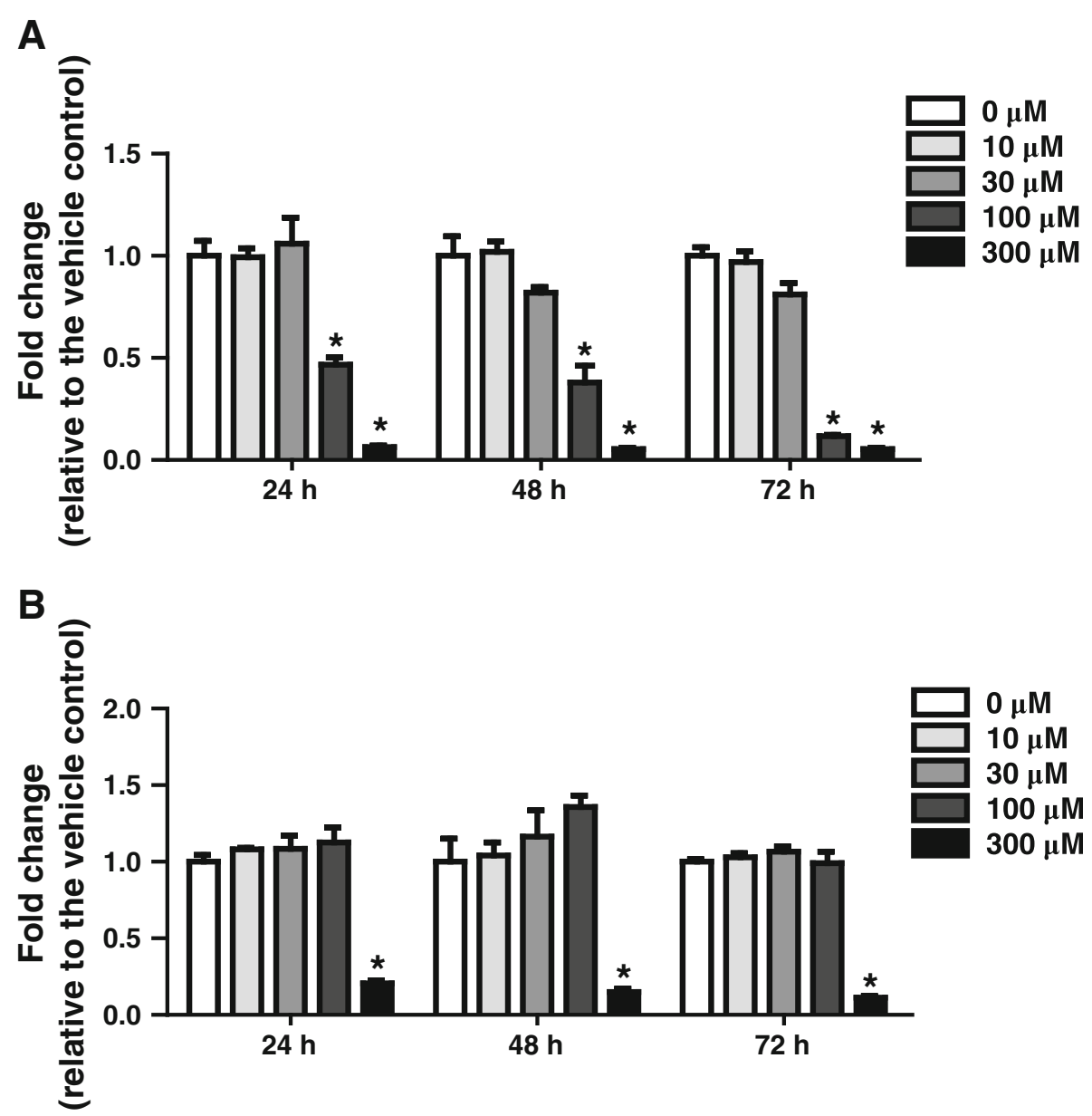

Figure 2 Evaluation of transepithelial electrical resistance (TEER) and cellular toxicity in $\mathbf{C d C l}_{2}$-treated human ALI cultures. Cultures were treated from the basolateral side with various concentrations of $\mathrm{CdCl}_{2}$ for 24,48 , or $72 \mathrm{~h}$. The cultures were washed briefly in PBS and TEER measurements (A) were conducted before processing the cultures for cytotoxicity evaluation using the MTS assay (B). Data ( $N=3)$ are presented as means \pm standard deviation. ${ }^{*} p<0.05$ was considered to be significant compared to the vehicle-treated control.

control cultures, both ZO-1 and occludin exhibited a well-defined localization around cell borders, indicating the presence of intact TJs (Figure 3, panels $A$ and $B$ ). The merged images of ZO-1 and occludin fluorescence staining further revealed their colocalization at the TJs (Figure 3, panel $D$ ). Treatments with $30 \mu \mathrm{M}$ and $50 \mu \mathrm{M}$ of $\mathrm{CdCl}_{2}$ did not alter the TJ integrity and colocalization of ZO-1 and occludin after $24 \mathrm{~h}$ (Figure 3, panels $E$ and $F$ and panels $I$ and $J$ ), an observation consistent with the TEER measurement (Figure 2A). After the 24-h treatment with $100 \mu \mathrm{M} \mathrm{CdCl}_{2}$, however, the staining of these two TJ markers was not limited to cellular boundaries as observed in vehicle-treated control group. Both ZO-1 and occludin exhibited partial membrane delocalization and redistribution to the cytoplasm (Figure 3, panels $M$ and $N$ ). It was noteworthy that $\mathrm{CdCl}_{2}$ only partially disrupted TJs at $100 \mu \mathrm{M}$, as the colocalization of ZO-1 and occludin at cellular boundaries was still visible in some areas of the cultures.
Acute treatment with $\mathrm{CdCl}_{2}$ modulates genes associated with TJs

The human TJ RT ${ }^{2}$ Profiler PCR array was used to measure the relative expression of 84 genes involved in TJ assembly and regulation. Cultures were treated basolaterally with vehicle, $30 \mu \mathrm{M}$ and $100 \mu \mathrm{M} \mathrm{CdCl}_{2}$ for $24 \mathrm{~h}$. The selection of the doses was based upon the extent of TJ disruption elicited by these doses inferred from the TEER measurements and staining for ZO-1 and occludin.

Nineteen genes had average threshold cycles greater than 30 and thus were excluded from the subsequent analysis. Principal component analysis (PCA) was performed to investigate the relationships for gene expression among the samples from the different dose groups (Figure 4). The vehicle-treated control samples and the low dose samples were loosely grouped together, indicating a minimum effect on gene expression associated with the $30 \mu \mathrm{M} \mathrm{CdCl}{ }_{2}$ treatment. Samples treated with $100 \mu \mathrm{M} \mathrm{CdCl}_{2}$ were more tightly grouped together and separated from both the 


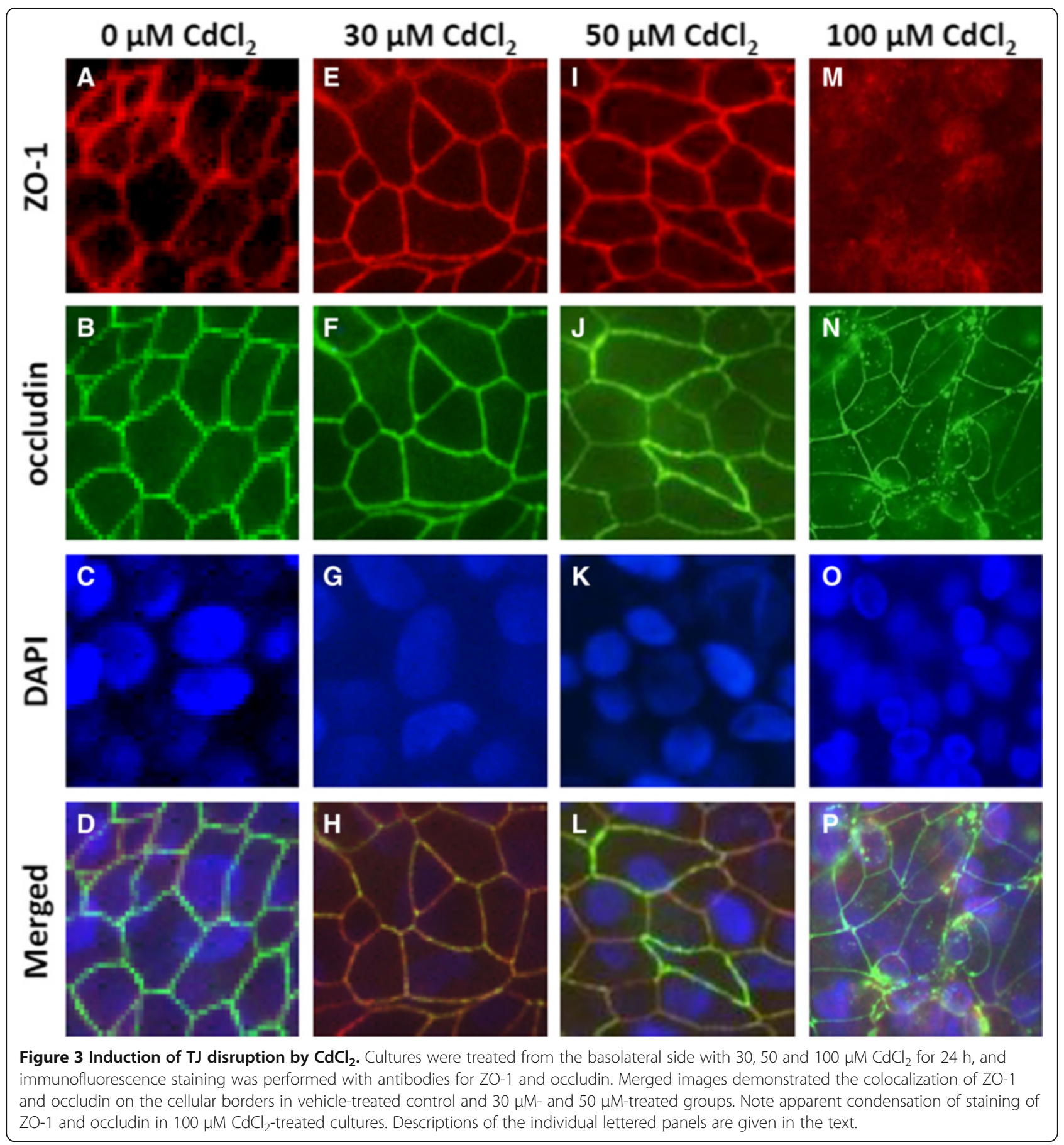

vehicle-treated control and low dose groups. Principal component 1 was found to be a convenient parameter to differentiate the treatment effects elicited by different doses of $\mathrm{CdCl}_{2}$.

Using the criteria defined in our study, 3 genes were modulated by $30 \mu \mathrm{M} \mathrm{CdCl}_{2}$ and 29 genes exhibited significant changes in their expression ratios (treatment/control) in response to the $100 \mu \mathrm{M} \mathrm{CdCl} 2$ treatment (Table 1). Among the 29 genes that demonstrated marked changes to $100 \mu \mathrm{M} \mathrm{CdCl}, 11$ genes were up-regulated and 18 genes were down-regulated. Notably, claudin 2 displayed differential responses to the $30 \mu \mathrm{M}$ - and $100 \mu \mathrm{M}$ treatments.

Genes that were differentially expressed are involved in a wide range of TJ-related biological processes, including cell surface receptors, the junction-interacting complex, G protein signaling, and protein kinase signaling (Figure 5 ). Nearly $40 \%$ of the genes differentially expressed by $100 \mu \mathrm{M} \mathrm{CdCl}_{2}$ were involved with the functions of the cytoplasmic junctional-protein complex. Cell surface 


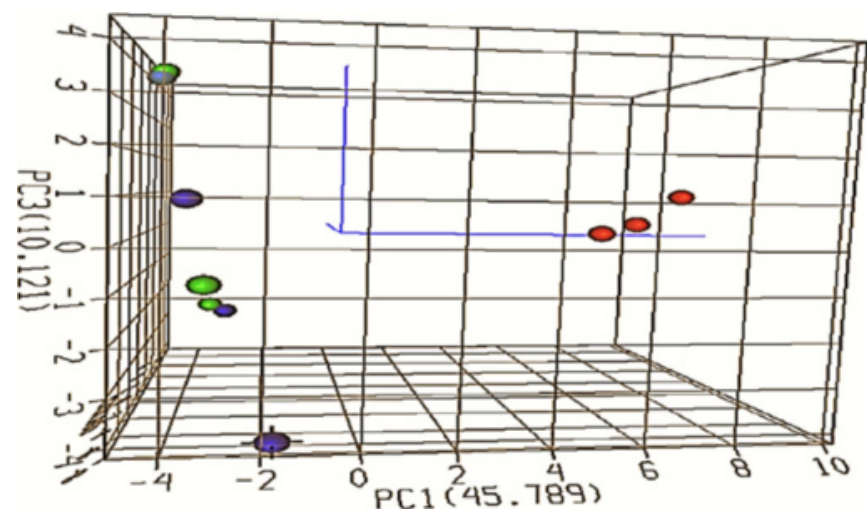

\section{Blue: $0 \mu \mathrm{M} \mathrm{CdCl}_{2}$ Green: $30 \mu \mathrm{M} \mathrm{CdCl}_{2}$ Red: $100 \mu \mathrm{M} \mathrm{CdCl}_{2}$}

Figure 4 3D depiction of principal component analysis (PCA) of gene expression in cultures treated with vehicle, $30 \mu \mathrm{M} \mathrm{CdCl} 2$, or $100 \mu \mathrm{M} \mathrm{CdCl}_{2}$. Sixty five genes that met the criteria defined by the $\mathrm{RT}^{2}$ Profiler PCR Array Data Analysis v3.5 software from SABiosciences were uploaded to the ArrayTrack program. The PCA is based on the $\log _{2}$ ratios and expression profiles across all the 65 genes in the PCR array. The blue, green, and red dots indicate cultures treated with vehicle, $30 \mu \mathrm{M} \mathrm{CdCl}_{2}$, and $100 \mu \mathrm{M} \mathrm{CdCl}_{2}$, respectively. The first three principal components are plotted. The captured variance of PC1 (first principal component), PC2 (second principal component; the label is not shown), and PC3 (third principal component) were $45.79 \%, 31.70 \%$, and $10.12 \%$, respectively.

receptors and protein kinase signaling molecules also were among the top groups of genes that were significantly modulated by $\mathrm{Cd}$ exposure.

Since genes involved in the junctional-protein complex were among the top gene groups modulated by $100 \mu \mathrm{M}$ $\mathrm{CdCl}_{2}$, three differentially expressed junctional-interacting genes, e.g., cingulin, tight junction interaction protein 1 (TJAP1), and VAP-33, were selected and changes in their protein expression were further examined by immunoblotting. Cingulin and TJAP1 exhibited clear dosedependent decreases in their protein expression with increasing concentrations of $\mathrm{CdCl}_{2}$; the expression of VAP33 also was decreased but its decrease was less doseresponsive (Figure 6A). Quantitative assessment, however, indicated that treatment with $100 \mu \mathrm{M} \mathrm{CdCl}$ decreased the expression of all three junctional-interacting proteins by approximately $50 \%$, decreases that were statistically significant (Figure 6B).

\section{Inhibitors of c-Src and PKC preserve TJ integrity by inhibiting occludin Tyr phosphorylation, rather than reversing the down-regulation of junctional interacting proteins}

We postulated that kinase activation might be involved in Cd-mediated TJ disruption. To test our hypothesis, ALI cultures were treated with $100 \mu \mathrm{M} \mathrm{CdCl} 2$ in the presence or absence of inhibitors of c-Src or PKC. The biological consequences of kinase inhibition on TJ integrity were examined by immunofluorescence staining of ZO-1 and occludin. Treatment of ALI cultures with either kinase inhibitor alone did not change the staining patterns of ZO-1 and occludin, both of which were localized on cellular borders (not shown) as observed in vehicle-treated control cultures (Figure 7A, panels $a$ and $b$ ). Consistent with our initial observations, $100 \mu \mathrm{M}$ $\mathrm{CdCl}_{2}$ partially disrupted TJ integrity (Figure 7A, panels $e$ through $h$ ). Concurrent treatment with $\mathrm{CdCl}_{2}$ and the kinase inhibitors, however, effectively preserved the intact TJ structures, as demonstrated by the welldefined staining for ZO-1 and occludin and their colocalization along the cellular borders (Figure 7A, panels $i$ through $p$ ).

The effects of kinase inhibition on the protein expression of the select junctional-interacting proteins were further explored by immunoblotting. Cotreatment with either of the kinase inhibitors did not prevent the $\mathrm{CdCl}_{2}-$ induced down-regulation of these proteins (Figure 7B). Approximate $50 \%$ decreases in the expression of cingulin and VAP-33 $(p<0.05)$ were observed in all treated groups compared to the control; while the expression of TJAP1 also was decreased in all treated groups, cotreatment with $\mathrm{CdCl}_{2}$ and the PKC inhibitor failed to significantly downregulate its expression (Figure $7 \mathrm{C}$ ).

Since the protective effect of the kinase inhibitors on TJ disruption did not appear to involve the junctionalinteracting proteins, we postulated that $\mathrm{Cd}$ exposure might alter the phosphorylation status of occludin on Tyr residues, and consequently cause TJ collapse. Because of the lack of an antibody specifically recognizing $\mathrm{p}$-Tyroccludin, occludin was first enriched by immunoprecipitation of equal amounts of whole cell lysate and Tyr-phosphorylated occludin was detected in the eluate using an antibody raised against Tyr-phosphorylated proteins. The level of total occludin was similar in all treatment groups (Figure 7D, upper panel). Treatment with $\mathrm{CdCl}_{2}$ increased occludin Tyr phosphorylation by approximately 2.5 -fold (Figure 7D, lower panel, lane 4 vs. lane 1). Concurrent treatment with $\mathrm{CdCl}_{2}$ and inhibitors 
Table 1 Significantly regulated $\mathrm{TJ}$-related genes in response to $\mathrm{CdCl}_{2}$ treatment in human airway epithelial $\mathrm{ALI}$ cultures (fold change $\geq 1.5, p$ value $<0.05$ )

\begin{tabular}{|c|c|c|c|c|c|c|}
\hline \multirow{2}{*}{$\begin{array}{l}\text { Gene } \\
\text { name }\end{array}$} & \multirow[t]{2}{*}{ Gene description } & \multirow[t]{2}{*}{ Biological function } & \multicolumn{2}{|c|}{ Group $1(30 \mu \mathrm{M})$} & \multicolumn{2}{|c|}{ Group $2(100 \mu \mathrm{M})$} \\
\hline & & & Fold change & $p$ value & Fold change & $p$ value \\
\hline \multicolumn{7}{|c|}{ Up-regulated } \\
\hline ICAM1 & Intercellular adhesion molecule 1 & Cell surface receptors & & & 13.89 & 0.000114 \\
\hline CRB3 & Crumbs homolog 3 (Drosophila) & Cell surface receptors & & & 3.95 & 0.000507 \\
\hline CLDN1 & Claudin 1 & Cell surface receptors & & & 2.99 & 0.000232 \\
\hline CLDN4 & Claudin 4 & Cell surface receptors & & & 2.57 & 0.012412 \\
\hline OCLN & Occludin & Cell surface receptors & & & 2.53 & 0.000418 \\
\hline ARHGEF2 & Rho/rac guanine nucleotide exchange factor 2 & G Protein signaling & & & 2.15 & 0.007405 \\
\hline CLDN2 & Claudin 2 & Cell surface receptors & & & 2.14 & 0.045285 \\
\hline TJP1 & Tight junction protein 1 (Zona occludens-1) & Junction interacting proteins & & & 2.13 & 0.00451 \\
\hline SMURF1 & SMAD specific E3 ubiquitin protein ligase 1 & $\begin{array}{l}\text { Cytoskeleton Regulator/ } \\
\text { G Protein Signaling }\end{array}$ & & & 1.71 & 0.005857 \\
\hline CLDN12 & Claudin 12 & Cell surface receptors & & & 1.65 & 0.008749 \\
\hline JAM3 & Junctional adhesion molecule 3 & Junction interacting proteins & & & 1.62 & 0.015438 \\
\hline AMOTL1 & Angiomotin like 1 & $\begin{array}{l}\text { Junction interacting proteins/ } \\
\text { Cytoskeleton regulation }\end{array}$ & 1.99 & 0.009748 & & \\
\hline HCLS1 & Hematopoietic cell-specific Lyn substrate 1 & Junction interacting proteins & 1.62 & 0.017181 & & \\
\hline \multicolumn{7}{|c|}{ Down-regulated } \\
\hline MPDZ & Multiple PDZ domain protein & Junction interacting proteins & & & -7.35 & 0.000001 \\
\hline PTEN & Phosphatase and tensin homolog & Protein kinase signaling & & & -4.22 & 0 \\
\hline ICAM2 & Intercellular adhesion molecule 2 & Cell surface receptors & & & -4.01 & 0.019093 \\
\hline CGN & Cingulin & Junction interacting proteins & & & -3.74 & 0.007739 \\
\hline CDK4 & Cyclin-dependent kinase 4 & G Protein signaling & & & -3.58 & 0.012422 \\
\hline CLDN16 & Claudin 16 & Cell surface receptors & & & -3.15 & 0.000298 \\
\hline MAGI1 & $\begin{array}{l}\text { Membrane associated guanylate kinase, WW and } \\
\text { PDZ domain containing } 1\end{array}$ & $\begin{array}{l}\text { Junction interacting proteins/ } \\
\text { Protein kinase signaling }\end{array}$ & & & -3.13 & 0.000032 \\
\hline CLDN8 & Claudin 8 & Cell surface receptors & & & -2.77 & 0.000306 \\
\hline CLDN2 & Claudin 2 & Cell surface receptors & -1.96 & 0.03226 & & \\
\hline GNAl1 & $\begin{array}{l}\text { Guanine nucleotide binding protein (G protein), } \\
\text { alpha inhibiting activity polypeptide } 1\end{array}$ & G Protein signaling & & & -2.70 & 0.000373 \\
\hline VAPA & $\begin{array}{l}\text { VAMP (vesicle-associated membrane protein)- } \\
\text { associated protein A, 33kDa }\end{array}$ & Junction interacting proteins & & & -2.20 & 0.000723 \\
\hline TJAP1 & Tight junction associated protein 1 (peripheral) & Junction interacting proteins & & & -2.20 & 0.028018 \\
\hline ASH1L & Ash1 (absent, small, or homeotic)-like (Drosophila) & Cytoskeleton Regulator & & & -2.14 & 0.000877 \\
\hline SYMPK & Symplekin & Junction interacting proteins & & & -2.07 & 0.040784 \\
\hline CSNK2A2 & Casein kinase 2, alpha prime polypeptide & Protein kinase signaling & & & -1.97 & 0.004506 \\
\hline CSDA & Cold shock domain protein A & $\begin{array}{l}\text { Junction interacting proteins/ } \\
\text { Cytoskeleton regulator }\end{array}$ & & & -1.73 & 0.000039 \\
\hline MPP6 & $\begin{array}{l}\text { Membrane protein, palmitoylated } 6 \text { (MAGUK p55 } \\
\text { subfamily member 6) }\end{array}$ & Protein kinase signaling & & & -1.71 & 0.0007 \\
\hline MLLT4 & $\begin{array}{l}\text { Myeloid/lymphoid or mixed-lineage leukemia } \\
\text { (trithorax homolog, Drosophila); translocated to, } 4\end{array}$ & Junction interacting proteins & & & -1.60 & 0.014185 \\
\hline CSNK2A1 & Casein kinase 2, alpha 1 polypeptide & Protein kinase signaling & & & -1.55 & 0.002999 \\
\hline
\end{tabular}

for $\mathrm{C}-\mathrm{Src}$ or PKC effectively prevented the increase in occludin phosphorylation (Figure 7D, lower panel, lanes 2 and 3 vs. lane 4 ).

\section{Discussion}

In this study, we investigated the effects of $\mathrm{Cd}$ on the integrity of TJs formed in an in vitro airway ALI tissue 


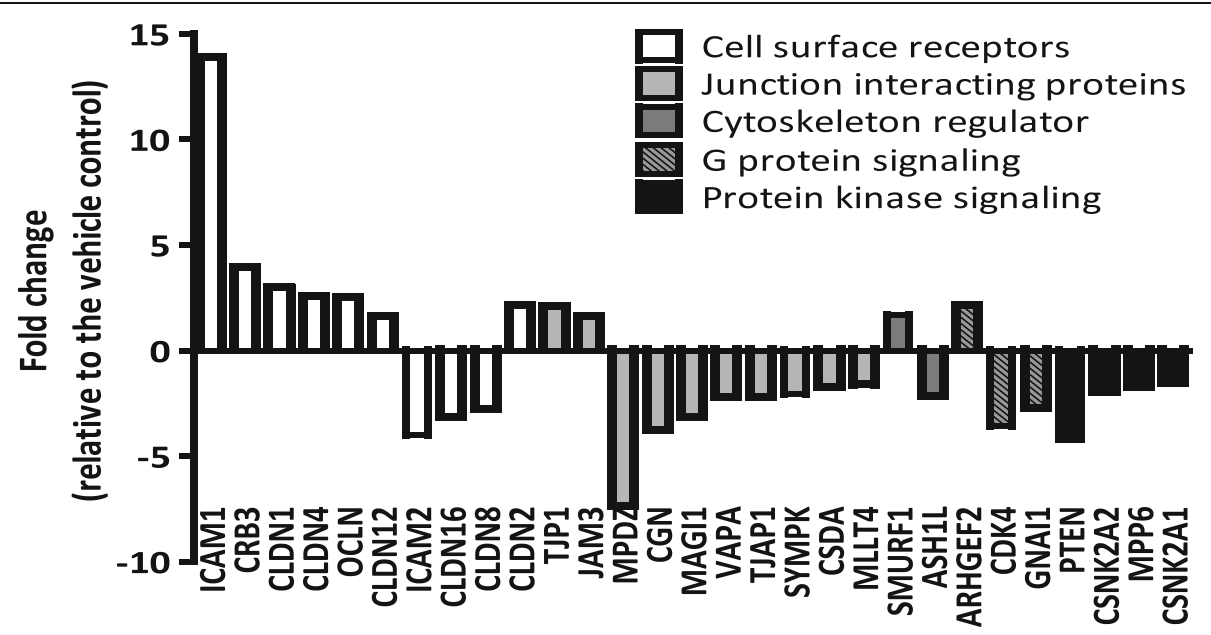

Figure 5 Expression changes of TJ-related genes in cultures exposed basolaterally to $100 \mu \mathbf{M ~ C d C l}_{2}$. The means of the gene expression changes are plotted. All genes presented here have a fold change $\geq 1.5$ and $p$-value $<0.05$. $N=4$ for vehicle-treated control group; $N=3$ for $100 \mu \mathrm{M} \mathrm{CdCl}$-treated group.

model derived from primary NHBE cells. Cd was selected as a test compound because of its reported disruption of TJs formed by many cell types [7-10] and its potential for airway exposure due to its presence in cigarette smoke [20]. Exposure of respiratory epithelium can occur by two routes, directly to the luminal (air interface) side of the airway through exposure to $\mathrm{Cd}$ in aerosols (e.g., cigarette smoke) or by systemic exposure to Cd circulating in the blood. In our study we exposed the ALI cultures from the basolateral side by adding $\mathrm{Cd}$

\section{A}

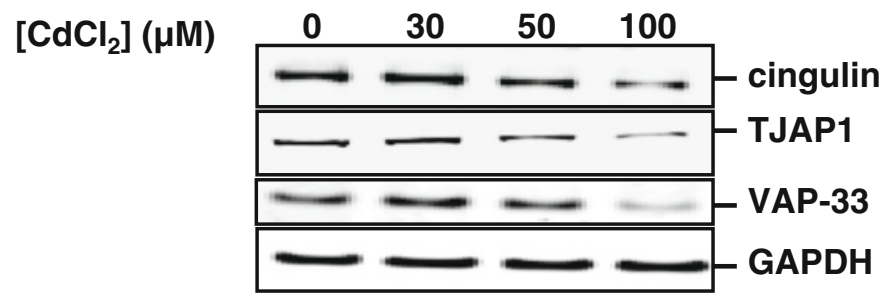

B

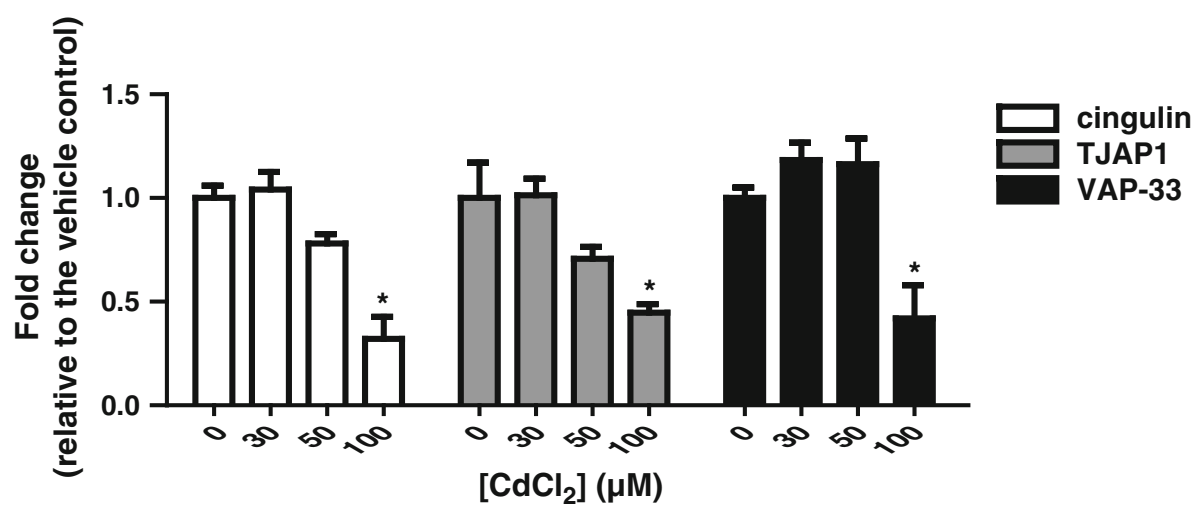

Figure 6 Cingulin, TJAP1, and VAP-33 protein expression changes in response to $\mathrm{CdCl}_{2}$ treatment. Cultures were treated from the basolateral side with various concentrations of $\mathrm{CdCl}_{2}$ for $24 \mathrm{~h}$, and whole cell lysate was collected and separated by electrophoresis. The expression of cingulin, TJAP1, and VAP-33 was detected by immunoblotting using specific antibodies. (A). Representative Western blots. (B). Density of the bands were quantified and statistically analyzed $(\mathrm{N}=3)$. ${ }^{*}$ Indicates $\mathrm{p}<0.05$ compared to the vehicle-treated control. 


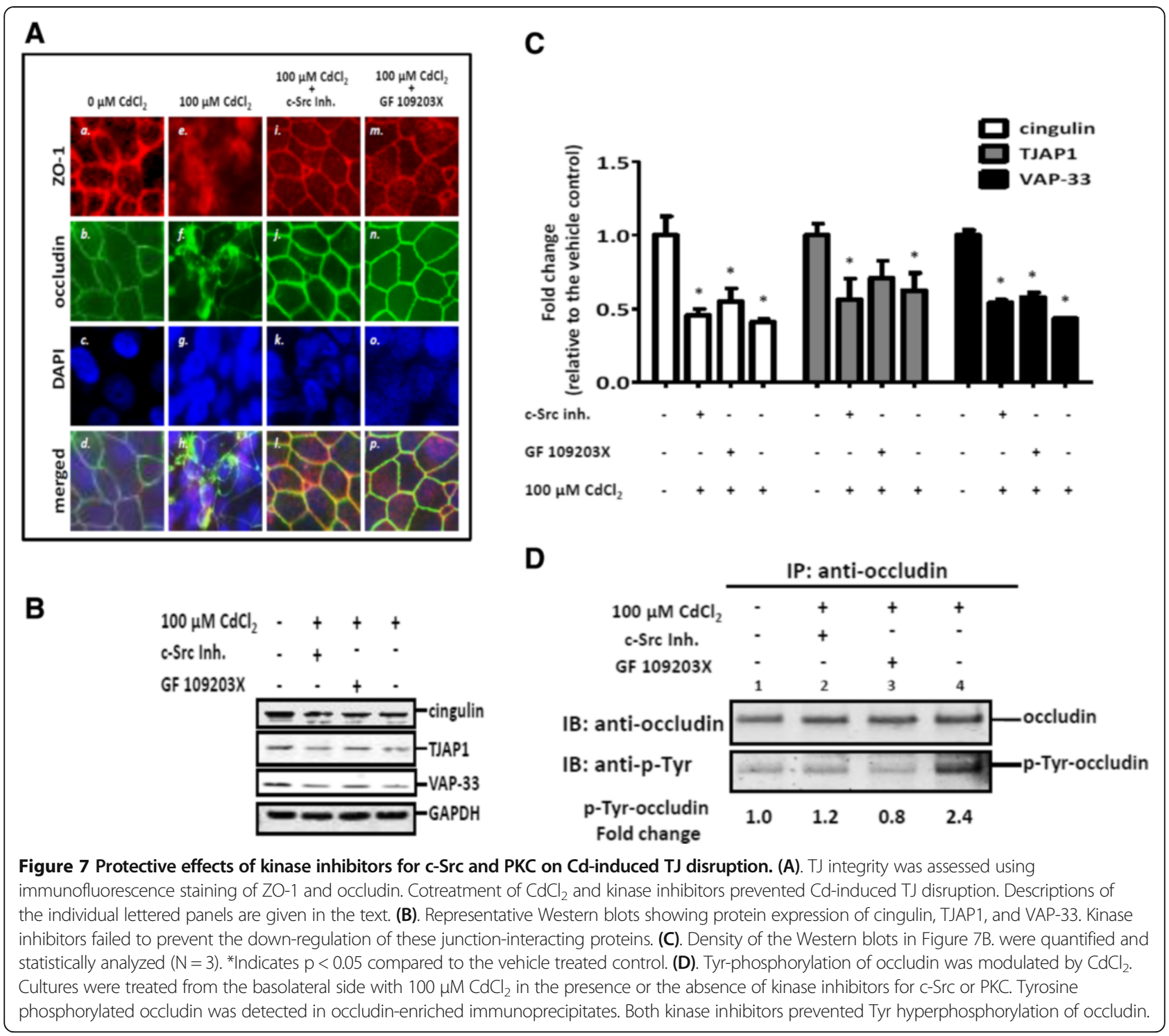

to the basal medium. This exposure mimics a biologically relevant route of exposure (i.e., systemic exposure), but also was done for a practical reason. Apical exposure of ALI culture would ideally use an aerosol of the test agent delivered in appropriately designed exposure chambers. Exposure of ALI cultures to aqueous solutions of $\mathrm{Cd}$ (e.g., dissolved in a small volume of PBS or $\mathrm{H}_{2} \mathrm{O}$ ) from the apical side is possible, albeit less of a mimic of in vivo respiratory exposure. However, we found that the aqueous vehicle temporarily affects $\mathrm{TJ}$ integrity. We observed that a 24-h treatment at the air-liquid interface with only PBS significantly decreased TEER values, an effect that was reversible several hours after removal of the PBS. Basolateral exposure avoids this temporary and possibly confounding factor that apparently results when the apical side of ALI cultures is covered. Apical exposures, using appropriate exposure systems, would provide additional information to inform a more complete accounting of $\mathrm{Cd}$ toxicity to airway ALI cultures.

The results of our study confirmed that the structure of the in vitro ALI cultures closely resembles the tissue architecture of in vivo airway epithelium. We further demonstrated that noncytotoxic doses of $\mathrm{CdCl}_{2}$ (measured by the MTS assay) compromised TJ barrier function likely via two independent mechanisms, i.e., by up-regulating occludin Tyr phosphorylation via kinase activation and by directly disrupting the junctional-interacting complex crucial for $\mathrm{TJ}$ biogenesis and signaling.

The reported blood levels of $\mathrm{Cd}$ in smokers [2] are much lower than the doses of $\mathrm{CdCl}_{2}$ that produced significant changes in $\mathrm{TJ}$ integrity in the ALI cultures. It should be noted that the half-life of $\mathrm{Cd}$ is greater than 
10 years in humans, and Cd is known to bind to cellular macromolecules and accumulate in cells [2]. Therefore, acute exposure of the ALI cultures may greatly underestimate the effects of chronic exposure to low doses of $\mathrm{Cd}$. We hypothesize that $\mathrm{TJ}$ disruption by more physiologically relevant concentrations of $\mathrm{Cd}$ may require longer treatment durations, allowing the accumulation of $\mathrm{Cd}$ and manifestation of its toxic effects following repeated exposures. Observations made from our acute-treatment study provide insights into the possible mechanisms of $\mathrm{Cd}$ toxicity; however, they cannot exclude the possibility that $\mathrm{TJ}$ disruption occurs following longer treatment durations with low doses of $\mathrm{Cd}$. Although longer treatments were not attempted in this study, one of the advantages of the airway ALI tissue model is that it maintains its functional and structural properties from weeks to months so that longer term exposures conducted in such models are possible. Note also that the airway models used in our study were prepared from cells derived from the large airways of human lung tissue. ALI cultures also can be prepared using primary cells from human small airway and alveolar tissue and these should be investigated for TJ disruption by $\mathrm{Cd}$ in future studies.

Human TJ PCR array and western blotting revealed the dysregulation of the junctional-interacting complexassociated proteins as a possible mechanism for $\mathrm{Cd}$ mediated TJ disruption. The junctional-interacting complex is a multi-molecular structure located in the cytoplasm and involved in bridging membranous $\mathrm{TJ}$ components with the actin cytoskeleton. VAP-33 has been implicated in the early recruitment of occludin to TJs and alteration in its expression results in dislocation of occludin from $\mathrm{TJ}$ patches [17]. Cingulin is found to connect TJ proteins with actin cytoskeletons through its head sequence and transmit signals during $\mathrm{TJ}$ biogenesis and regulation [21-23]. TJAP1 is incorporated at late stages of TJ assembly, and thus is postulated to have a possible role in stabilizing TJ plaques [24]. Considering their multiple functions at various stages of $\mathrm{TJ}$ homeostasis, the Cd-induced dysregulation of the junctional interacting proteins observed in our study could have taken place in a staged manner, with down-regulation of VAP-33 occurring after TJAP1 and cingulin, resulting in several possible downstream effects, such as disassembly of the protein-junctional complex, disruption of the actin cytoskeleton, dysregulation of TJ signal transduction, and increased barrier permeability due to redistribution of $\mathrm{TJ}$ proteins, eventually leading to the collapse of TJs. In fact, previous reports have demonstrated that Cd-mediated junction interruption is accompanied by disruption of the actin-based cytoskeleton in other in vitro cell model systems $[25,26]$. Thus, our observations, in conjunction with these previous studies, support a possible signaling cascade triggered during Cd-induced TJ disruption involving dysregulation of both the actin cytoskeleton and junctional-interacting proteins that function as cytoskeletal adaptor proteins in pulmonary airway epithelium.

Consistent with the report of Dokladney et al. [27], our study also indicates that the protein expression of occludin is not affected by $\mathrm{Cd}$ exposure, at least at the concentrations tested. Rather, our observations suggest a role for c-Src and PKC in Cd-mediated post-translational modification of occludin in human airway epithelial ALI cultures. Co-administration of c-Src or PKC inhibitors prevented Cd-induced occludin Tyr hyperphosphorylation and the collapse of TJs, suggesting that kinase activation may be an early cellular event triggered by $\mathrm{Cd}$ exposure. This effect of $\mathrm{Cd}$ on protein kinase activity is not unprecedented; $\mathrm{Cd}$ induces conformational changes and modulates the enzymatic activities of protein kinases by either directly binding to their metal-binding dicysteine-containing motifs or substituting for essential metals, such as $\mathrm{Zn}^{2+}$, in their regulatory domains $[28,29]$. For kinases that are involved in TJ maintenance and regulation, modulation of their activities by $\mathrm{Cd}$ may elicit a cascade of related down-stream signaling, resulting in the collapse of TJ integrity. For instance, occludin Tyr hyperphosphorylation by kinase activation may attenuate its interaction with other $\mathrm{TJ}$ components, leading to its subcellular dislocalization and ultimately, weakening of the TJ structures. It is noteworthy that kinase signaling pathways become dysregulated in several smoking-related pulmonary diseases, such as in non-small cell lung cancer, asthma, chronic obstructive pulmonary disease, and idiopathic pulmonary fibrosis [30]. Thus, modulations of various kinase activities by $\mathrm{Cd}$ in these disease settings warrant further investigation.

Several protein kinases modulate TJ barrier functions through occludin phosphorylation. c-Src directly binds to the C-terminal domain of occludin, and Tyr residues Y398/Y402 were identified as the c-Src phosphosites [31,32]. Activation of c-Src by oxidative stress weakens the barrier properties of Caco- 2 cells, and is accompanied by the redistribution of occludin and the $\mathrm{TJ}$-associated protein ZO-1 from cellular borders to the cytoplasm [33]. Other protein kinases, such as $\mathrm{PKC}$, also are implicated in phosphorylating occludin and modulating $\mathrm{TJ}$ permeability. However, the exact role of the PKC family in occludin phosphorylation and TJ regulation is less clear. Different isoforms of PKCs may regulate $\mathrm{TJ}$ integrity by exerting inhibitory or stimulatory effects on occludin phosphorylation in different cellular systems and under different conditions [18]. Even though they mainly catalyze the phosphorylation modifications on Thr and Ser residues, the possible involvement of PKCs in Tyr phosphorylation revealed by our study is consistent with a study conducted on rat hippocampal slices demonstrating direct Tyr phosphorylation of the N-methyl-D-aspartate receptor by PKC 
activation [34]. Alternatively, it also is possible that Ser and Thr phosphorylation of occludin by PKC activation renders the Tyr residues more susceptible to phosphorylation by c-Src activation, thus suggesting an indirect involvement of $\mathrm{PKC}$ in occludin Tyr phosphorylation in response to $\mathrm{Cd}$ exposure.

\section{Conclusions}

Our studies suggest a plausible mechanism for $\mathrm{Cd}$ toxicity in human airway ALI models. Given the protective effect of kinase inhibitors on TJ integrity, kinase activation is believed to be an early up-stream cellular event triggered by $\mathrm{Cd}$ exposure. Furthermore, Tyr hyperphosphorylation of occludin by kinase activation could potentially attenuate occludin interactions with other junctional-interacting proteins and lead to its dislocation from the cytoplasmic membrane. Based on the fact that the kinase inhibitors did not reverse $\mathrm{Cd}$-induced down-regulation of the select junctional-interacting proteins, we conclude that $\mathrm{Cd}$ disrupts $\mathrm{TJ}$ integrity through at least two independent mechanisms. Besides causing kinase activation and subsequently downstream occludin Tyr hyperphosphorylation, Cd also may directly disrupt the junction interacting complex by inhibiting gene expression for junctional interacting proteins independent of kinase signaling. The direct inhibition of junctionalinteracting protein genes may occur through binding of $\mathrm{Cd}$ to the promoter region of their DNA. We hypothesize that these combined effects alter the microenvironment of $\mathrm{TJ}$ plaques and contribute to compromising the TJ barrier. We, however, view our observations as a starting point for understanding the toxicity of $\mathrm{Cd}$ in airway tissue. Further studies should be conducted to explore the effects of apical exposure of the airway tissue models to aerosolized $\mathrm{Cd}$ using systems that mimic in vivo exposures, and also to evaluate the effects of chronic apical and basolateral exposures to low doses of $\mathrm{Cd}$. It also is possible that $\mathrm{Cd}$ affects TJ integrity differently in different parts of the airway, and studies similar to ours should be conducted using ALI cultures prepared from small airway and alveolar cells.

\section{Abbreviations}

Cd: Cadmium; TJ: Tight junction; ALI: Air-liquid-interface; TEER: Trans-epithelial electrical resistance; PKC: Protein kinase C; ZO-1: Zonula occludens-1; NHBE: Normal primary human bronchial epithelial; TJAP1: Tight junctionassociated protein 1; BEGM: Bronchial epithelium growth medium; PBS: Phosphate-buffered saline; H\&E: Hematoxylin and eosin; BSA: Bovine serum albumin; DAB: Diaminobenzidine; PAS: Periodic acid-Schiff; EVOM2: Epithelial volt-ohmmeter 2; DAPI: 4',6-diamidino-2-phenylindole; MTS: A tetrazolium compound; PCA: Principal component analysis; co-IP: Co-immunoprecipitation; BCA: Bicinchoninic acid; ANOVA: Analysis of variance.
}

\section{Competing interests}

The authors declare that they have no competing interests.

\section{Authors' contributions}

XC contributed to the experimental design, coordinated the study, performed the experiments, and drafted the manuscript. HL performed the study and contributed to experimental design. LM and $J L$ conducted the histopathological evaluation of the ALI cultures. PR and RH provided guidance on experimental design and contributed to data interpretation. All authors read and approved the final manuscript.

\section{Acknowledgements}

The authors would like to thank the Center for Tobacco Products for the financial support. The authors also would like to thank Lisa Freeman for her technical assistance with the pathology analysis.

\section{Disclaimer}

The information and views expressed are those of the authors and do not necessarily represent the views of the Food and Drug Administration or of the U.S. government.

\section{Funding}

This work is supported by U.S. Food and Drug Administration funding through the Center for Tobacco Products (this study was conducted between March and August of 2013). H.L was supported by a post-doctoral fellowship through the Oak Ridge Institute for Science and Education through an interagency agreement between the U.S. Department of Energy and the U.S. Food and Drug Administration.

\section{Author details}

${ }^{1}$ U.S. Food and Drug Administration/National Center for Toxicological Research, Jefferson, AR 72205, USA. ${ }^{2}$ Toxicologic Pathology Associates, Jefferson, AR 72079, USA. ${ }^{3}$ U.S. Center for Disease Control and Prevention, Atlanta, GA 30333, USA. ${ }^{4}$ Division of Genetic and Molecular Toxicology, 3900 NCTR Rd, Jefferson, AR 72079, USA.

Received: 26 September 2014 Accepted: 10 February 2015

Published online: 21 February 2015

\section{References}

1. Pinot F, Kreps SE, Bachelet M, Hainaut $P$, Bakonyi M, Polla BS. Cadmium in the environment: sources, mechanisms of biotoxicity, and biomarkers. Rev Environ Health. 2000;15:299-323.

2. Järup L, Berglund M, Elinder CG, Nordberg G, Vahter M. Health effects of cadmium exposure-a review of the literature and a risk estimate. Scand J Work Environ Health. 1998;24 Suppl 1:1-52.

3. Richter PA, Bishop EE, Wang J, Swahn MH. Tobacco smoke exposure and levels of urinary metals in the U.S. youth and adult population: the National Health and Nutrition Examination Survey (NHANES) 1999-2004. Int J Environ Res Public Health. 2009;6:1930-46.

4. Messner B, Bernhard D. Cadmium and cardiovascular diseases: cell biology, pathophysiology, and epidemiological relevance. Biometals. 2010;23:811-22.

5. Waalkes MP. Cadmium carcinogenesis in review. J Inorg Biochem. 2000;79:241-4

6. Waisberg M, Joseph P, Hale B, Beyersmann D. Molecular and cellular mechanisms of cadmium carcinogenesis. Toxicology. 2003;192:95-117.

7. Forti E, Bulgheroni A, Cetin Y, Hartung T, Jennings P, Pfaller W, et al. Characterisation of cadmium chloride induced molecular and functional alterations in airway epithelial cells. Cell Physiol Biochem. 2010;25:159-68.

8. Hew KW, Heath GL, Jiwa AH, Welsh MJ. Cadmium in vivo causes disruption of tight junction-associated microfilaments in rat Sertoli cells. Biol Reprod. 1993;49:840-9.

9. Prozialeck WC, Lamar PC, Lynch SM. Cadmium alters the localization of $\mathrm{N}$-cadherin, E-cadherin, and $\beta$-catenin in the proximal tubule epithelium. Toxicol Appl Pharmacol. 2003;189:180-95.

10. Siu ER, Wong EWP, Mruk DD, Sze KL, Porto CS, Cheng CY. An occludin-focal adhesion kinase protein complex at the blood-testis barrier: a study using the cadmium model. Endocrinology. 2009;150:3336-44.

11. Aijaz S, Balda MS, Matter K. Tight junctions: molecular architecture and function. Int Rev Cytol. 2006;248:261-98.

12. Balda MS, Matter K. Tight junctions at a glance. J Cell Science. 2008;121:3677-82.

13. Sawada N. Tight junction-related human diseases. Pathol Int. 2013;63:1-12. 
14. Blasig IE, Bellmann C, Cording J, del Vecchio G, Zwanziger D, Huber O, et al. Occludin protein family: oxidative stress and reducing conditions. Antioxid Redox Signal. 2011;15:1195-219.

15. Capaldo CT, Nusrat A. Cytokine regulation of tight junctions. Biochim Biophys Acta. 2009;1788:864-71

16. Furuse $\mathrm{M}$, Itoh $\mathrm{M}$, Hirase $\mathrm{T}$, Nagafuchi $\mathrm{A}$, Yonemura S, Tsukita S, et al. Direct association of occludin with ZO-1 and its possible involvement in the localization of occludin at tight junctions. J Cell Biol. 1994;127:1617-26.

17. Lapierre LA, Tuma PL, Navarre J, Goldenring JR, Anderson JM. VAP-33 localizes to both an intracellular vesicle population and with occludin at the tight junction. J Cell Sci. 1999;112:3723-32

18. Dörfel MJ, Huber O. Modulation of tight junction structure and function by kinases and phosphatases targeting occludin. J Biomed Biotechnol. 2012;2012:article ID 807356

19. Coyne CB, Vanhook MK, Gambling TM, Carson JL, Boucher RC, Johnson LG. Regulation of airway tight junctions by proinflammatory cytokines. Mol Biol Cell. 2002;13:3218-34.

20. U.S Department of Health and Human Services: How tobacco smoke causes disease: the biology and behavioral basis for smoking-attributable disease. A report of the Surgeon General. 2010

21. Aijaz S, D'Atri F, Citi S, Balda MS, Matter K. Binding of GEF-H1 to the tight junction-associated adaptor cingulin results in inhibition of Rho signaling and G1/S phase transition. Dev Cell. 2005;8:777-86.

22. Gonzalez-Mariscal L: Tight junctions. Landes Bioscience and Springer Science Business Media 2006

23. Guillemot L, Hammar E, Kaister C, Ritz J, Caille D, Jond L, et al. Disruption of the cingulin gene does not prevent tight junction formation but alters gene expression. J Cell Sci. 2004;117:5245-56.

24. Kawabe H, Nakanishi H, Asada M, Fukuhara A, Morimoto K, Takeuchi M, et al. Pilt: a novel peripheral membrane protein at tight junctions in epithelial cells. J Biol Chem. 2001;296:48350-5.

25. Prozialeck WC, Niewenhuis RJ. Cadmium $\left(\mathrm{Cd}^{2+}\right)$ disrupts intercellular junctions and actin filaments in LLC-PK 1 cells. Toxicol Appl Pharmacol. 1991;107:81-97.

26. Xiao X, Mruk DD, Tang El, Wong CKC, Lee WM, John CM, et al. Environmental toxicants perturb human Sertoli cell adhesive function via changes in F-actin organization mediated by actin regulatory proteins. Hum Reprod. 2014;29:1279-91.

27. Dokladny K, Wharton W, Ma TY, Moseley PL. Lack of cross-tolerance following heat and cadmium exposure in functional MDCK monolayers. J Appl Toxicol. 2008;28:885-94.

28. Ahmadibeni Y, Hanley M, White M, Ayrapetov M, Lin X, Sun G, et al. Metal-binding properties of a dicysteine-containing motif in protein tyrosine kinases. Chembiochem. 2007;8:1592-605.

29. Beyersmann D, Block C, Malviya AN. Effects of cadmium on nuclear protein kinase C. Environ Health Perspect. 1994;102 Suppl 3:177-80.

30. Lam J, Levine SJ: The role of tyrosine kinases in the pathogenesis and treatment of lung disease. In Advances in Protein Kinases, Chapter 8. Edited by Da Silva Xavier G. InTech; 2012

31. Elias BC, Suzuki T, Seth A, Giorgianni F, Kale G, Shen L, et al. Phosphorylation of Tyr-398 and Tyr-402 in occludin prevents its interaction with ZO-1 and destabilizes its assembly at the tight junctions. J Biol Chem. 2009;284:1559-69.

32. Kale G, Naren AP, Sheth P, Rao RK. Tyrosine phosphorylation of occludin attenuates its interactions with ZO-1, ZO-2, and ZO-3. Biochem Biophys Res Commun. 2003;302:324-9.

33. Basuroy S, Sheth P, Kuppuswamy D, Balasubramanian S, Ray RM, Rao RK. Expression of kinase-inactive c-Src delays oxidative stress-induced disassembly and accelerates calcium-mediated reassembly of tight junctions in the Caco-2 cell monolayer. J Biol Chem. 2003;278:11916-24.

34. Grosshans DR, Browning MD. Protein kinase $C$ activation induces tyrosine phosphorylation of the NR2A and NR2B subunits of the NMDA receptor. J Neurochem. 2001;76:737-44.

\section{Submit your next manuscript to BioMed Central and take full advantage of:}

- Convenient online submission

- Thorough peer review

- No space constraints or color figure charges

- Immediate publication on acceptance

- Inclusion in PubMed, CAS, Scopus and Google Scholar

- Research which is freely available for redistribution 